\section{Minimum bactericidal concentration of phenols extracted from oil vegetation water on spoilers, starters and food-borne bacteria}

\author{
Luca Fasolato,' Barbara Cardazzo, ${ }^{1}$ \\ Stefania Balzan, ${ }^{1}$ Lisa Carraro, ${ }^{1}$ \\ Agnese Taticchi, ${ }^{2}$ Filomena Montemurro, ${ }^{1}$ \\ Enrico Novelli' \\ 'Department of Comparative Biomedicine \\ and Food Science, University of Padua, \\ Legnaro (PD); ' 2 Department of \\ Agricultural, Food and Environmental \\ Sciences, University of Perugia, Italy
}

\section{Abstract}

The aim of the study was to assess the in vitro effect of phenols extracted from oil vegetation water (PEOW) on several food-borne strains. Antibacterial activity of PEOW was based on the minimum bactericidal concentration (MBC) on microtitre assay. The taxa tested were: Staphylococcus (n. 5), Listeria (n. 4), Escherichia (n. 2), Salmonella (n. 1), Pseudomonas (n. 3), Lactobacillus (n. 2) and Pediococcus (n. 1). S. aureus and L. monocytogens showed the lowest level of resistance to PEOW (MBC=1.5-3 mg/mL). In contrast, the Gram negative strains (e.g. S. Typhimurium and Pseudomonas spp.) were in some cases unaffected by the tested doses and the MBCs ranged between 6 to $12 \mathrm{mg} / \mathrm{mL}$. Starter cultures were dramatically reduced on growth (e.g. Staphylococcus xylosus; $0.75 \mathrm{mg} / \mathrm{mL}$ MBC). The thresholds for pathogenic strains could be considered for further applications of PEOW in food models (e.g. shelf life or challenge test studies).

\section{Introduction}

Due to their bioactive properties, some vegetables or their extracts have been applied to a large number of human activities (e.g. food preservation) since ancient times (Medina et al., 2006). In particular, a wide range of plant extracts showed certain levels of inhibition against bacterial growth. In most cases, the antibacterial activity is attributed to the presence of phenolic compounds that are metabolites involved in the resistance against parasites (Servili et al., 2011a, 2011b).

Olives, virgin olive oil and its secondary products such as olive mill wastewater showed a high level of phenolic compounds. The gluco- side oleuropein is the main phenolic compound (secoiridoids) in fruit; moreover in olive products the molecules of its hydrolysis exert a stronger antimicrobial activity (Medina et al., 2006). However, most part of these compounds is lost in wastewater during the olive oil extraction process. It was recognized that the presence of phenolic compounds reduces the microbial degradability of oil vegetation waters (VWs) leading to pollution problems (Capasso et al., 1995; Tafesh, et al., 2011; Saadi et al., 2007) However, VWs could be considered as additional resources for the virgin olive oil (VO0) industry. In fact several phenolic compounds occurring in VW, having the same chemical characteristics of VOO phenols, possess many biological properties that include antioxidant activity and, for this reason, may be used in food industry as natural preservatives or bio-active ingredients (Servili et al., 2011b).

The aim of the study was to assess the in vitro bactericidal effect of purified phenols extracted from oil vegetation water (PEOW) obtained by membrane filtration techniques from VW on several food-borne strains (spoilage bacteria, food-borne pathogens and starter cultures). The assessment of bactericidal activity could define some threshold doses for a further application on real food models.

\section{Materials and Methods}

In Figure 1 the protocol for the separation of the phenols extracted from oil vegetation water is reported.

A panel of 18 food-borne strains was investigated for the minimum bactericidal concentration (MBC; Table 1) in a microtiter assay. Several two-fold dilutions of the PEOW (Figure 1) were performed in a $20 \%$ ethanol/water solution $(12.0 ; 6.0 ; 3.0 ; 1.5 ; 0.75 ; 0.375 \mathrm{mg} / \mathrm{mL})$, considering a $65 \%$ of total phenolic content on the initial extract (Carraro et al., 2014). Strains were grown overnight and then diluted to obtain a standardized inoculum. Each well was added with $50 \mu \mathrm{L}$ of PEOW and $200 \mu \mathrm{L}$ of bacterial suspension in a 96 well plate with a final bacterial concentration of $10^{5} \mathrm{UFC} / \mathrm{mL}$

For each plate 3 wells without bacteria were performed according PEOW dilution (negative control). Moreover, for each strain 3 wells were added with $200 \mu \mathrm{L}$ of bacterial suspension and $50 \mu \mathrm{L}$ of a $20 \%$ ethanol/water solution; an additional positive control was performed for each strain using $250 \mu \mathrm{L}$ of bacterial suspension. Microtiter plates were incubated at specific temperature/time for each strains and the MBC was evaluated on agar plate by spreading $10 \mu \mathrm{L}$ of each suspension. The dose that kills the bacteria was recorded and the MBC was defined as the level that did not allowed the
Correspondence: Luca Fasolato, Department of Comparative Biomedicine and Food Science, University of Padua, viale dell'Università 16, 35020 Legnaro (PD), Italy.

Tel: +39.049.8272965 - Fax: +39.049 .8272604 .

E-mail: luca.fasolato@unipd.it

Key words: Phenols; Food-borne bacteria; Olive vegetation water; $\mathrm{MBC}$.

Acknowledgements: the authors thank Angiolella Lombardi (Veneto Agricoltura), Marilena Marino (University of Udine), Renzo Mioni (Institute for Experimental Veterinary Medicine of Venice) for providing some strains.

Received for publication: 8 July 2014.

Revision received: 23 October 2014.

Accepted for publication: 20 December 2014

This work is licensed under a Creative Commons Attribution 3.0 License (by-nc 3.0).

(C) Copyright L. Fasolato et al., 2015

Licensee PAGEPress, Italy

Italian Journal of Food Safety 2015; 4:4519

doi:10.4081/ijfs.2015.4519

survival of all replicates. A visual examination of well bottoms was also applied in order to have a visible growth and define the minimum inhibitory concentration (MIC). Three different biological replicates were performed for each plate and all experiments were duplicates.

\section{Results}

Table 1 reported the MBC value for the foodborne bacteria tested. Among pathogenic strains, $S$. aureus and $L$. monocytogens showed the lowest level of resistance to PEOW $(\mathrm{MBC}=1.5-3 \mathrm{mg} / \mathrm{mL})$. For Gram positive strains, some events of heteroresistance were observed and a stringent evaluation of $\mathrm{MBC}$ was based on the highest level that did not allowed the growth on all replicates. On the opposite, in Gram negative strains (e.g $S$. Typhimurium and Pseudomonas spp.) the MBCs ranged between 6 to $12 \mathrm{mg} / \mathrm{mL}$ with the exception of Escherichia coli 0:157 H7 (3 $\mathrm{mg} / \mathrm{mL}$ ). Starter cultures were dramatically reduced in growth (e.g. S. xylosus; MBC 0.75$1.5 \mathrm{mg} / \mathrm{mL}$ ). Pediococcus pentosaceus seemed the more resistant species among actic acid bacteria (LAB), the strain was able to survive at higher concentrations of PEOW (MBC 12 $\mathrm{mg} / \mathrm{mL}$ ). The ethanol/water solution did not affect the survival of any tested strains, the results were in agreement with the previously observation on E. coli (Carraro et al., 2014). The final concentration of ethanol was around 
$1 / 4$ of the initial solution (5\%), this level was ineffective to kill the pre-inoculum of the tested bacteria.

The MIC is the lowest concentration of an antimicrobial that inhibit the growth of a microorganism. The visual examination has resulted in some misinterpretation due to the turbidity of the extract after the incubation, especially at higher PEOW concentrations (6$12 \mathrm{mg} / \mathrm{mL}$ ); for this reason the evaluation of MIC is not reported.

\section{Discussion}

As reported by Carraro et al. (2014) the composition of the extract showed that Oleuropein-aglycone di-aldehyde was the major secoiridoid constituent $(471.7 \pm 1.9$ $\mathrm{mg} / \mathrm{g})$. Others chemical compounds are Hydroxytyrosol $(72.7 \pm 0.6 \mathrm{mg} / \mathrm{g})$, Tyrosol (17.8 $\pm 0.1 \mathrm{mg} / \mathrm{g})$ and Verbascoside $(83.6 \pm 1.0$ $\mathrm{mg} / \mathrm{g}$ ). The bactericidal effect was linked to a combination of these substances. The in vitro tests suggested an interesting bactericidal effect of PEOW, especially on Gram positive food-borne pathogens. Other studies reported that $S$. aureus and L. monocytogenes showed a higher sensitivity to phenols derived from several olive matrices (e.g olive oil, olive leaf and purified compounds) (Medina et al., 2006; Pereira et al., 2007). Moreover, Thafesh et al. (2011) suggested that the use of a combina-

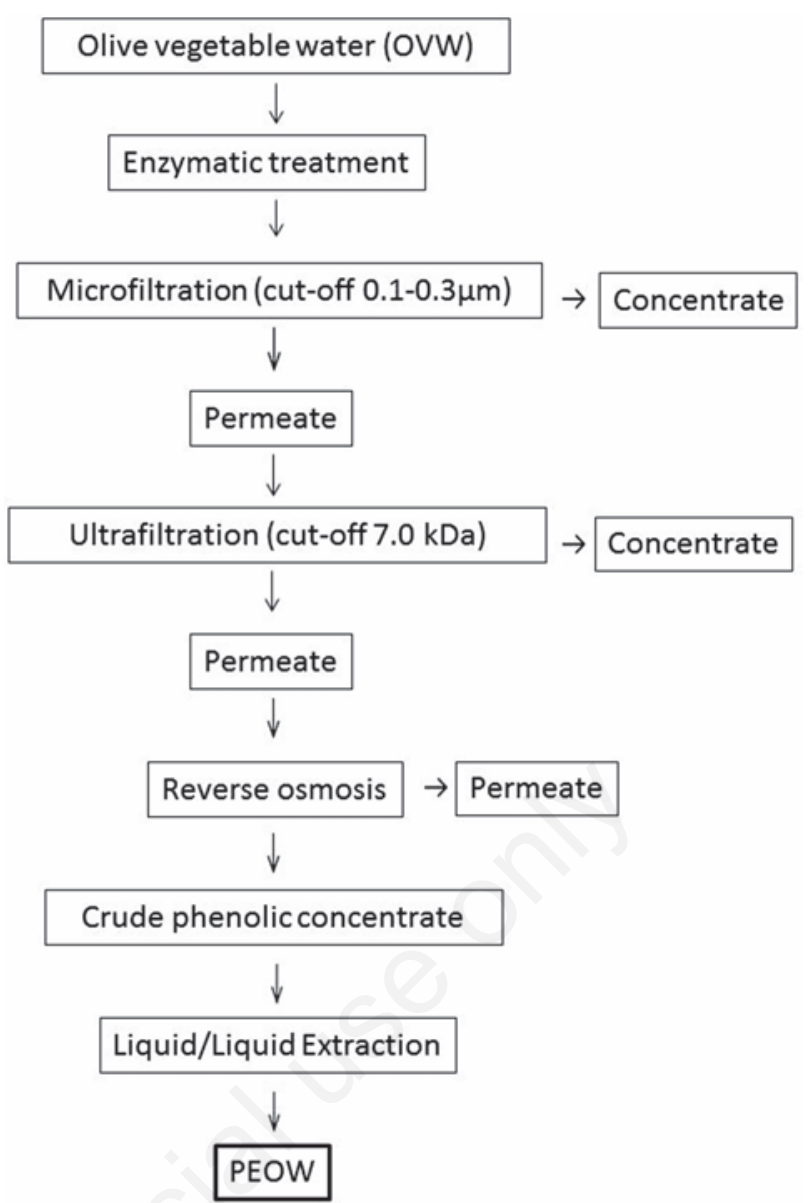

Figure 1. Protocol for the separation of the phenols extracted from oil vegetation water from olive vegetable water. Based on Servili et al. (2011a).

Table 1. Species, origin and growth mediums of the strains tested in the study and their relative minimum bactericidal concentration.

\begin{tabular}{|c|c|c|c|c|}
\hline Species & Origin & Medium & Temperature $\left({ }^{\circ} \mathrm{C}\right)$ - incubation $(\mathrm{h})$ & MBC $(\mathrm{mg} / \mathrm{mL})$ \\
\hline Staphylococcus aureus ATCC 29213 & Wound & LB and agar & $37-24$ & 1.5 \\
\hline Staphylococcus aureus LMG 8224 & Clinic isolate & LB and agar & $37-24$ & 3 \\
\hline Staphylococcus aureus $415^{*}$ & Salami & LB and agar & $37-24$ & 1.5 \\
\hline Listeria monocytogenes 21962 AL 8/4 & Food & LB and agar & $37-24$ & 3 \\
\hline Listeria monocytogenes $1271^{*}$ & Salami & LB and agar & $37-24$ & 3 \\
\hline Listeria monocytogenes LMG 13305 & Fresh cheese & LB and agar & $37-24$ & 3 \\
\hline Listeria innocua AТCC 33090 & Bovine brain & LB and agar & $37-24$ & 1.5 \\
\hline Escherichia coli 0:157 H7 NCTC 12900 & Human diarrhea & LB and agar & $37-24$ & 3 \\
\hline Escherichia coli LMG 8223 & Clinic isolate & LB and agar & $37-24$ & 6 \\
\hline Salmonella Typhimurium ATCC 14028 & Liver of hen & LB and agar & $37-24$ & 12 \\
\hline Pseudomonas fluorescens $\mathrm{MOZ3}^{\circ}$ & Mozzarella cheese & LB and agar & $22-48$ & 6 \\
\hline Pseudomonas fluorescens PS22\# & Mozzarella cheese & LB and agar & $22-48$ & 6 \\
\hline Pseudomonas aeruginosa $4 \mathrm{C}^{2} \mathrm{~T}^{\circ}$ & Stracchino cheese & LB and agar & $37-24$ & 6 \\
\hline Staphylococcus xylosus 100M SAl- $(3)^{\S}$ & Starter for salami & LB and agar & $30-48$ & 0.75 \\
\hline Staphylococcus xylosus SAl-100M (7) & Starter for salami & LB and agar & $30-48$ & 1.5 \\
\hline Lactobacillus curvatus SAl-100M (13) & Starter for salami & MRSB/agar & $30-48$ & 1.5 \\
\hline Lactobacillus curvatus SAl-100M (14) & Starter for salami & MRSB/agar & $30-48$ & 1.5 \\
\hline Pediococcus pentosaceus 923 CECT & Fermented milk & MRSB/agar & $30-48$ & 12 \\
\hline
\end{tabular}

MBC, minimum bactericidal concentration; LB, lysogeny broth. *Isolated by VenetoAgricoltura, Thiene (VI); ${ }^{\circ}$ isolated by University of Udine; \#isolated by Institute for Experimental Veterinary Medicine of

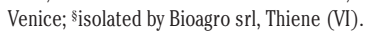


tion of polyphenols extracted by olive mill wastewater is effective against several human pathogens. The present results confirmed the potential of PEOW, though the bioactivity could be related to the content of certain specific phenolic compounds (Thafesh et al., 2011). As noted, the visual examination of MIC failed at higher concentrations of PEOW. This is probably due to the formation of a brown-coloured quinonic form due to the oxidative degradation of phenols. The present results suggested two thresholds of bactericidal effect on Gram positive food-borne pathogens. However, other pertinent considerations need to be considered when these products are added to the food (e.g organoleptic traits, diffusion, bonding with some food constituents).

\section{Conclusions}

Taking into account MBC results, the LAB and $S$. xylosus are among the most sensitive bacteria. In a functional milk beverage fortified with phenolic compounds Servili et al. (2011b) did not find a significant reduction in LAB growth. Still, the level of inclusion was limited (100 and $200 \mathrm{mg} / \mathrm{L}$ ). In other fermented products, the supplementation of higher levels of PEOW, as a natural ingredient, could reduce the performance or the quality of ripening. For further applications, a deep screening of starter cultures is required in order to select the species able to grow in presence of phenol during fermentation. The MBC suggested that one strain of Pediococcus pentosaceus was able to grow at $12 \mathrm{mg} / \mathrm{mL}$ : this species could be applied to some fermented food (e.g salami). These results highlighted the potential of PEOW against some food-borne bacteria. This work is the first step before the use of these substances on the food models (e.g. challenge test and storage test) for the further application of this extract as an ingredient. The two thresholds proposed for the pathogenic foodborne bacteria need to be considered together with other pertinent food aspects (e.g. organoleptic traits, antioxidant effects).

\section{References}

Capasso R, Evidente A, Schivo L, Orru G, Marcialis MA, Cristinzio G, 1995. Antibacterial polyphenols from olive oil mill wastewaters. J Appl Bacteriol 79:3938.

Carraro L, Fasolato L, Montemurro F, Martino ME, Balzan S, Servili M, Novelli E, Cardazzo B, 2014. Polyphenols from olive mill waste affect biofilm formation and motility in Escherichia coli K-12 L. Microb Biotechnol 7:265-75.

Medina E, Antonio DC, Concepcion R, Manuel $\mathrm{B}, 2006$. Comparison of the concentrations of phenolic compounds in olive oils and other plant oils: correlation with antimicrobial activity. J Agr Food Chem 54:495461.

Pereira AP, Ferreira ICFR, Marcelino F, Valentão P, Andrade PB, Seabra R, Estevinho L, Bento A, Pereira JA, 2007. Phenolic compounds and antimicrobial activity of olive (Olea europaea L. Cv. Cobrançosa) Leaves. Molecules 12:115362.

Saadi I, Laor Y, Raviv M, Medina S, 2007. Land spreading of olive mill wastewater: effects on soil microbial activity and potential phytotoxicity. Chemosphere 66:75-83.

Servili M, Esposto S, Veneziani G, Urbani S, Taticchi A, Di Maio I, Selvaggini R, Sordini B, Montedoro GF, 2011a. Improvement of bioactive phenol content in virgin olive oil with an olive-vegetation water concentrate produced by membrane treatment. Food Chem 124:1308-15.

Servili M, Rizzello CG, Taticchi A, Esposto S, Urbani S, Mazzacane F, Di Maio I, Selvaggini R, Gobbetti M, Di Cagno R, 2011b. Functional milk beverage fortified with phenolic compounds extracted from olive vegetation water, and fermented with functional lactic acid bacteria. Int J Food Microbiol 147:45-52.

Tafesh A, Naim N, Jeries J, Fares H, Herbert R, Hassan A, 2011. Synergistic antibacterial effects of polyphenolic compounds from olive mill waste water. Evid-Based Compl Alt 2011:1-9. 